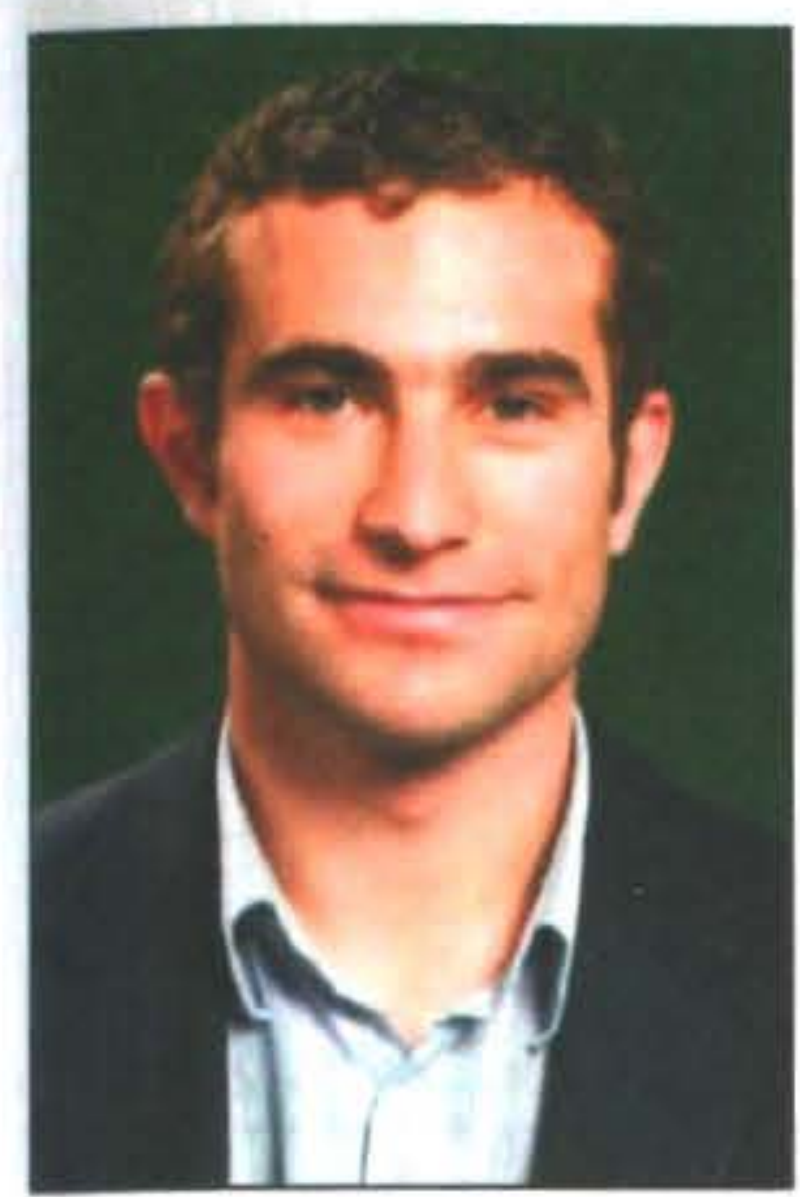

\title{
UNDERUTILISED LABOUR: MORE THAN THE UNEMPLOYED?
}

\author{
Simon Hall \\ Work Directions \\ Department of Labour
}

The official unemployment rate in New Zealand has been below 5\% for nearly six years and reached a 22-year low of $3.4 \%$ in late 2007. However, official unemployment statistics understate the availability of labour given they do not include an important group of people who want to work - the marginally attached. These are people who want to work, but are either not available or not actively seeking work and therefore are not classified as unemployed. But how different are those people that are marginally attached to the labour force compared to the unemployed? Since 1999, strong employment growth has coincided with a large drop in unemployment but the number of people marginally attached to the labour force has fallen only slightly. Using data from the Household Labour Force Survey, this paper tries to explain the reasons behind this by examining trends in those marginally attached to the labour force and whether this group is significantly different to the officially unemployed. While it is sometimes argued that those marginally attached to the labour force should be combined with the officially unemployed to give a measure of excess supply, this paper investigates whether this is sensible given they appear to be two distinct groups.

\section{Introduction}

Strong employment growth over the last decade has seen New Zealand's unemployment rate fall to very low levels in recent years. In December 2007, the unemployment rate fell to $3.4 \%$, the lowest ever recorded in the Household Labour Force Survey's 22-year history.

While a low unemployment rate is typically indicative of a tight labour market, it does not reveal the full extent of labour scarcity. One issue is the degree to which the official unemployment rate understates the availability of labour given there is a large group of people who want to work but do not fall into the officially unemployed. While this group of people want a job, they are either not actively seeking work or are not available to start a job within the next four weeks. Instead, these workers are classified as not in the labour force and are commonly referred to as "marginally attached" to the labour force.

Data from the Household Labour Force Survey show there are currently around 80,000 people outside the labour force who want a job. As a percentage of all people not in the labour force, this is a significant proportion of about $8 \%$. The people who make up this group are of considerable interest to labour market economists and policy makers given they represent underutilised labour.
Some would argue that combining the unemployed and the marginally attached offers a more complete picture of the slack or tightness of the labour market. But to what extent are those marginally attached to the labour force really considered surplus labour supply? By pooling them together with the officially unemployed, as Statistics New Zealand do with the jobless category, we are implicitly assuming that the two groups are similar. Yet during the latest expansion in employment, unemployment has fallen strongly but those marginally attached to the labour force has declined only slightly.

With the unemployment rate low, participation at a record high, and the population ageing, a major concern is where future labour supply is going to be sourced from. This paper investigates the characteristics of those marginally attached to the labour force, in an attempt to help us better understand this alternative source of potential labour supply. A better understanding of this group may help with the formation of policies which overcome the barriers these people face in entering employment.

\section{Data and definitions}

The data used in the analysis have been sourced from the Household Labour Force Survey (HLFS). The HLFS sample frame uses an eight-quarter panel, and samples approximately 30,000 individuals aged 15 and over and 15,000 households each quarter. 


\section{Defining the marginally attached}

To be classified as unemployed in the HLFS, a person must not be employed, must be available for work and has to have actively sought work in the past four weeks. However, the HLFS also captures information on people who satisfy only one of these conditions i.e. available for work but not seeking, and seeking work but not available to start within the next four weeks. These people are commonly referred to as "marginally attached" to the labour force and are captured by Statistics New Zealand in the jobless category. The jobless category includes both the officially unemployed and the marginally attached.

Within the marginally attached group is an important subset known as discouraged workers. These are people who want a job and are currently available for work but are not actively seeking work because they believe they lack skills, are the wrong age, or the right work was unavailable in their area. While it would be preferable to examine the characteristics of discouraged workers separately to other marginally attached workers, the small size of this group makes this difficult. As at September 2008, the HLFS only identified around 3,000 people who were discouraged workers.

\section{How do recent unemployment trends compare if we include those "marginally attached"?}

The current unemployment rate in New Zealand is $4.2 \%$. In absolute terms this translates to around 94,000 people unemployed. Yet in addition to those who are officially unemployed, a further 80,000 people or so indicate they want a job. If we include those marginally attached to the labour force, the unemployment rate, or jobless rate, rises to $7.2 \%$. In fact, since 1999 , including the marginally attached would lead to the unemployment rate being on average 3.3 percentage points higher than the unemployment rate. Over the latter part of this period, when the unemployment rate has been below $4 \%$, this is essentially a doubling of the official unemployment rate. Figure 1 shows the unemployment rate, the jobless rate and the marginally attached rate since 1987.

It can be argued that combining these two groups gives a more complete picture of labour availability, or labour market slack, as it includes everyone who wants to work. However, by adding these two groups together, essentially we are implying they are identical, or at least similar. But, what if these people lack the required skills to enter the workforce, or are not able to work due to caring responsibilities? Then in reality, the marginally attached may not be as "employable" as the unemployed.
Figure 1: Unemployment, jobless and marginally attached rates, 1987-2008

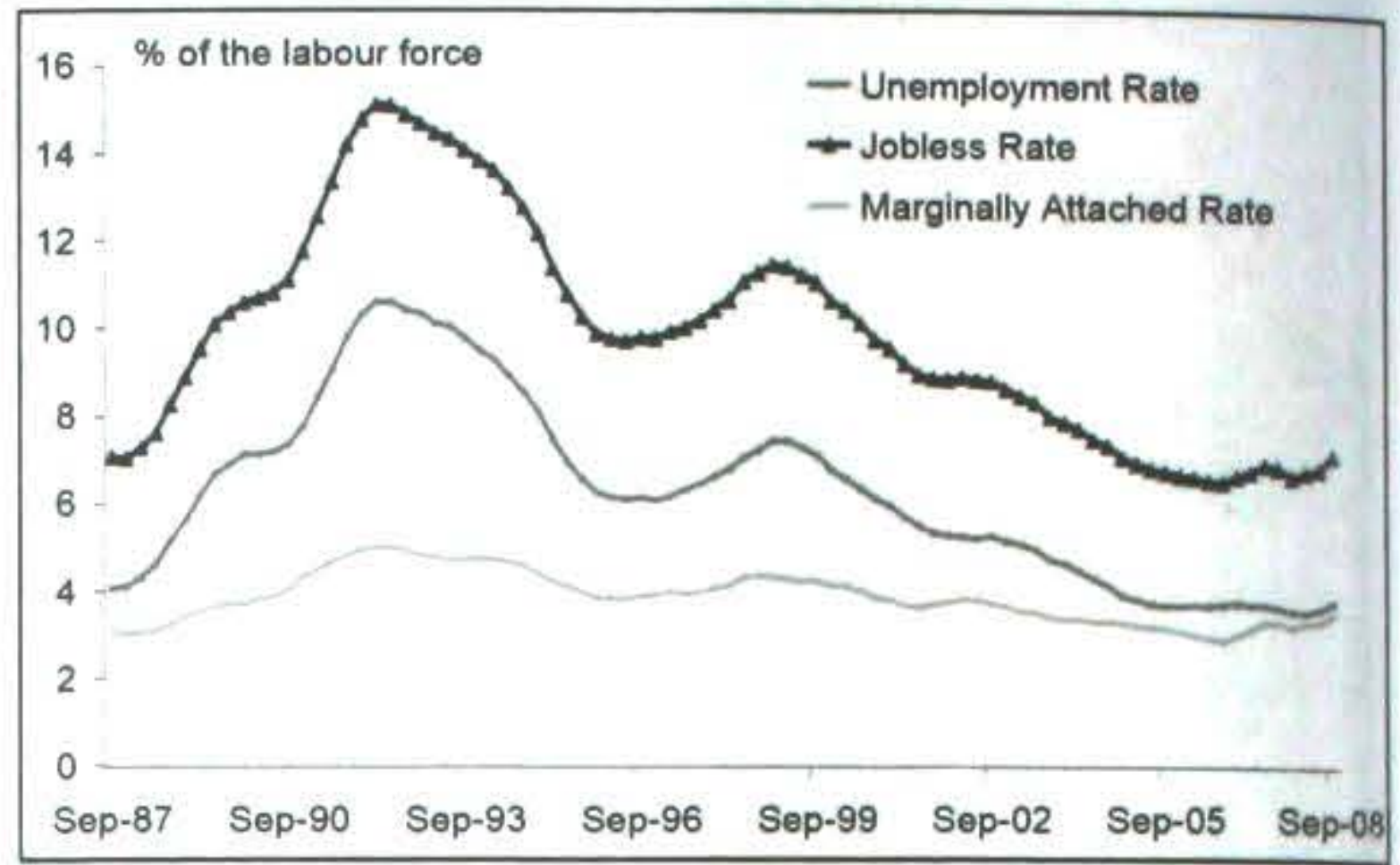

Source: HLFS, Statistics New Zealand.

\section{Where has employment growth been sourced from?}

Before considering the characteristics of those marginally attached to the labour force, it is helpful to examine what has driven employment growth in recent times.

Between March 1999 and 2008, employment has grown by an average of $2.3 \%$ per annum, and over 400,000 more people are in employment. This growth in employment is far stronger than growth in the workingage population, which has averaged $1.3 \%$ per annum over the last nine years. So what has driven the remainder of this increase in employment?

Figure 2 shows the different factors which have driven net employment growth over this period. Nearly twothirds $(60 \%)$, or around 240,000 , is the result of an increase in the working-age population while nearly onequarter $(23 \%)$, or about 90,000 , of employment growth has been driven by an increase in the rate at which people participate in the labour force. The annual average labour force participation rate was $68.4 \%$ in the year to March 2008, up strongly from $65.3 \%$ in the year to March 1999.

The remaining $17 \%$ of the increase in employment has been sourced from those unemployed and marginally attached to the labour force: $15 \%$ has been sourced from the unemployed while only $2 \%$ has been sourced from the marginally attached. The number of people unemployed has fallen from 141,000 in 1999 to 79,000 in 2008 , a decrease of $44 \%$. Over the same period, the number of people marginally attached to the labour force has fallen from 85,000 to around 76,000 , a fall of $10 \%$. 
Figure 2: Breakdown of net employment growth, 1999-2008

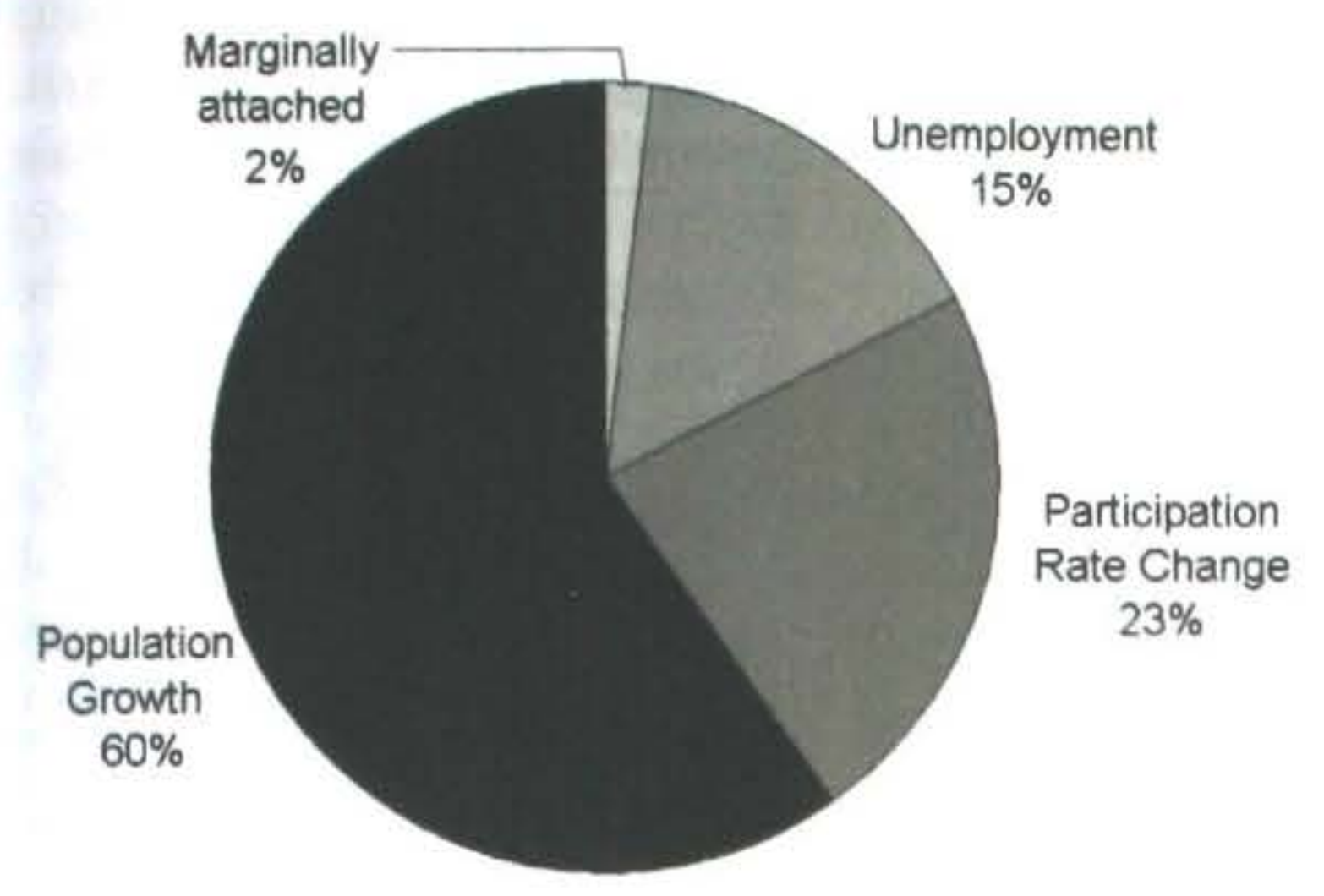

Source: HLFS, Statistics New Zealand.

That there has been such a large fall in unemployment relative to the fall in the number of people marginally attached suggests the dynamics and characteristics of these two groups may be different.

If we look at the previous expansion in employment, we also see similar patterns. Between 1992 and 1997, 25\% of the expansion in employment over that time was sourced from those unemployed while only $5 \%$ were from the marginally attached. Increases in the participation rate accounted for $20 \%$ of employment growth with population increase accounting for the remainder.

\section{Who are the marginally attached?}

This section examines the characteristics of those classified as marginally attached to the labour force and compares this with the characteristics of those unemployed for the 1999-2008 period. Comparisons are also made against those not in the labour force as we are interested in whether the marginally attached are more like other jobseekers (i.e. the unemployed) or more like other non labour force participants.

It is important to gain a better understanding of the characteristics of the marginally attached, given that relative to other labour market non-participants, they are perhaps more likely to be responsive to changes in government policy as they have the desire to work. It is also important in the context of considering where future labour supply is going to come from. Do the marginally attached want to work but don't have the skills or is it something else?

\section{Actively seeking but not available or available but not actively seeking?}

Over the 1999-2008 period, an average of $74 \%$ of people marginally attached to the labour force were available for work but not actively seeking. Of this $74 \%$, or 54,500 people, $22 \%$ stated they were not actively seeking because they were attending an educational institution, $19 \%$ were only looking through newspapers (which is considered to be passive rather than active searching), and $12 \%$ were discouraged, with the remainder being due to other reasons.

The other one-quarter $(26 \%)$ of those marginally attached are actively seeking work but are not available. This group is particularly important for targeting by government policy. If we can understand why they are not available for work then there is potential for policies to be introduced which remove the barriers to entry into the labour force. This could lead to participation gains and, in turn, greater economic activity.

Of the nearly 19,000 people who are actively seeking work but not available, $31 \%$ are attending an educational institution, $29 \%$ stated personal and family responsibilities and $11 \%$ had a temporary illness or injury with the remainder stating other reasons.

Education plays a big part in either not being available or not actively seeking work. It is hard to know exactly what students' motivations are for being available for work but not seeking it. It could be that work would provide useful but not absolutely necessary financial assistance during their education. As for those seeking work but not available, they may be affected by shortterm study commitments or be about to complete their education. Reasons such as these suggest that work is more of a casual concern for students in this group and that attachment to the job market could change quickly in future periods.

\section{Gender}

Women are more likely to be marginally attached than men with $57 \%$ of the marginally attached being female. The gender split amongst the unemployed is more even with women comprising just under one-half $(48 \%)$. However, nearly two-thirds $(63 \%)$ of people not in the labour force are female. The gender breakdown of the marginally attached is therefore positioned in the middle of the two groups.

Similar to the unemployed, being marginally attached to the labour force is for many a short-term situation as people complete study or look after family. One reason why there is a larger share of women amongst the marginaily attached could be due to mothers who are available for work but are unable to find suitable childcare. This was stated as a reason for not seeking work for around 3,500 women on average per quarter between 1999 and 2008.

While women are more likely to be marginally attached to the labour force, the proportion of men who are marginally attached has actually increased between 1999 and 2008 from $40 \%$ to $45 \%$. This contrasts with the proportion of males unemployed which has fallen from $57 \%$ in 1999 to $49 \%$ in 2008 . 
Table 1: Key characteristics of those marginally attached, unemployed and not in the labour force (average for the period March 1999-2008) (000s)

\begin{tabular}{|c|c|c|c|c|c|c|}
\hline & $\begin{array}{c}\# \\
\text { Marginally } \\
\text { Attached }\end{array}$ & $\begin{array}{c}\% \text { of } \\
\text { Marginally } \\
\text { Attached }\end{array}$ & \# Unemployed & $\begin{array}{c}\% \text { of } \\
\text { Unemployed }\end{array}$ & $\begin{array}{c}\# \\
\text { Not in the } \\
\text { Labour Force }\end{array}$ & $\begin{array}{c}\% \text { of } \\
\text { Not in the } \\
\text { Labour Force }\end{array}$ \\
\hline \multicolumn{7}{|l|}{ Gender } \\
\hline Male & 32,200 & $43 \%$ & 50,500 & $52 \%$ & 380,600 & $37 \%$ \\
\hline Female & 42,100 & $57 \%$ & 46.000 & $48 \%$ & 638,900 & $63 \%$ \\
\hline \multicolumn{7}{|l|}{ Age } \\
\hline $15-24$ & 29,900 & $40 \%$ & 39,100 & $40 \%$ & 206,200 & $20 \%$ \\
\hline $55+$ & 11,800 & $16 \%$ & 8,000 & $8 \%$ & 530,900 & $52 \%$ \\
\hline \multicolumn{7}{|l|}{ Region } \\
\hline North Island & 54.600 & $73 \%$ & 73,400 & $76 \%$ & 761,700 & $75 \%$ \\
\hline South Island & 19.800 & $27 \%$ & 23.200 & $24 \%$ & 257,800 & $25 \%$ \\
\hline \multicolumn{7}{|l|}{ Ethnicity } \\
\hline European/Pakeha & 44,200 & $60 \%$ & 55.200 & $57 \%$ & 740,700 & $73 \%$ \\
\hline Maori & 15,500 & $21 \%$ & 21,100 & $22 \%$ & 105,800 & $10 \%$ \\
\hline Pacific Peoples & 5.200 & $7 \%$ & 7.900 & $8 \%$ & 56,900 & $6 \%$ \\
\hline Other & 9.400 & $13 \%$ & 12.100 & $13 \%$ & 114,800 & $11 \%$ \\
\hline \multicolumn{7}{|l|}{ Qualification } \\
\hline No qualification & 25,800 & $35 \%$ & $30.5(0)$ & $32 \%$ & 405.400 & $40 \%$ \\
\hline School qualification & 21,900 & $30 \%$ & 25.500 & $27 \%$ & 285.500 & $28 \%$ \\
\hline Post-school qualification & 26.300 & $36 \%$ & 39,900 & $42 \%$ & 321,600 & $32 \%$ \\
\hline Total & 74.400 & $100 \%$ & 96,500 & $100 \%$ & $1,019,500$ & $100 \%$ \\
\hline
\end{tabular}

Source: HLFS, Statistics New Zealand. Numbers may not sum due to rounding.

\section{Age}

Marginal attachment appears to be more common at either end of the age spectrum. Compared to the unemployed, a disproportionate number of the marginally attached are aged over 55 . They account for $16 \%$ of the marginally attached group yet they make up only $8 \%$ of the unemployed. This could be explained by older persons being more likely to become discouraged in their job search by believing they have less chance of finding another job compared to younger workers. Despite having low unemployment rates, overseas studies have found older persons are more likely to be discouraged than the rest of the population (Kodrzycki 2000. Akyeampong 1989 and Rones 1983). The high proportion of those aged 55 and over among the marginally attached may also indicate some discrimination, or at least some perceived discrimination, by employers towards older workers.

More than half $(52 \%)$ of all people not in the labour force are aged 55 years and over with the large majority of these people retired. This could perhaps provide some more insight into why a larger proportion of the marginally attached are aged 55 years and over. There is evidence that a small number of older persons are partially retired and do not need to work but would work if the right job came along. Around 3,500 people stated they were available for work but were not actively seeking working because they had no need to work or because they were retired. This could be seen as some sort of forced retirement because they are discouraged, although it is perhaps more likely to reflect some sort of normal pre-retirement decrease in job search intensity. It has been suggested that as persons get closer to retirement, the return on job search investments declines due to a decrease in the time for which they can recoup their investment (Hairault, Chéron and Langot 2007).

At the other end of the age spectrum, a large percentage of the marginally attached are between 15-24 years of age. As with the unemployed, $40 \%$ are aged between 15 24. The reason why there is a large proportion of youth who are marginally attached is most likely to be similar to the reasons why there are high levels of youth unemployment. This is mainly related to young people leaving school without the skills or experience needed to enter employment (OECD 1999) and also many not being available due to being engaged in education.

Compared to 1999, the age distribution of the marginally attached and the unemployed have changed slightly. Within both groups there has been a large increase in the number of youth, while decreases have occurred in just about all of the other age groups.

\section{Ethnicity}

The ethnic composition of the marginally attached is similar to the unemployed for the 1999-2008 period. Compared to those not in the labour force and the working-age population as a whole, Europeans are under represented while Maori are over represented. Maori represent $21 \%$ and $22 \%$ of the marginally attached and the unemployed respectively, while they comprise only $10 \%$ of the working-age population and of those not in 
the labour force. Maori being over represented amongst the marginally attached can probably be attributed to the same reasons why Maori are over-represented in unemployment, which can partly be explained by factors such as age structure, educational attainment and location (Mare 1995). Pacific peoples and 'Other' ethnicities are also slightly over represented in both groups.

Between 1999 and 2008, there has been a small fall in the percentage of Europeans in the marginally attached and the unemployed groups and a noticeable rise in the 'Other' ethnic group.

\section{Region}

There appear to be no significant differences between the marginally attached and the unemployed by region. Around three-quarters of the unemployed and the marginally attached are located in the North Island with one-quarter in the South Island. This is similar to the regional breakdown found for those not in the labour force and is representative of the working-age population as a whole. There also appears to be no major differences when the three groups are examined by rural and urban area. This is slightly surprising, given the marginally attached can include people who are not actively seeking work because they believe that the right work is unavailable in their area.

Over the nine years to 2008 , there appears to have been a slight increase in the percentage of marginally attached and the unemployed in the North Island relative to the South Island. The South Island now has some very low rates of unemployment and joblessness, particularly in Southland, parts of Otago (e.g. Queenstown-Lakes) and Nelson/Tasman/Marlborough.

\section{Qualifications}

The marginally attached are more likely to have no qualification when compared to the rest of the workingage population and the unemployed. For the 1999-2008 period, an average of $35 \%$ of the marginally attached had no qualification compared to $26 \%$ of the working-age population and $32 \%$ of the unemployed. This is not too surprising given the age structure of the marginally attached. The large proportion of youth, who are generally too young to have obtained a qualification, and of people aged over 55 , who are more likely to have no qualifications, can explain this. The marginally attached were more likely to have qualifications than those not in the labour force with $40 \%$ having no qualification.

Nearly one-half $(48 \%)$ of the current working-age population have a post-school qualification. This compares with $36 \%$ of those marginally attached and $42 \%$ of the unemployed. With education arguably the most important predictor of labour market participation (Laplagne, Glover, Shomos 2007), this suggests the marginally attached are less likely to enter into employment than the unemployed.

Between 1999 and 2008, the percentage of the marginally attached and the unemployed with postschool qualifications has remained around the same level. There has been a decrease in the percentage with no qualifications in both groups which is consistent with the overall trend in the working-age population.

\section{How are the marginally attached affected by economic and labour market conditions?}

In the above section, it was shown that the characteristics of the marginally attached indicated they were less likely to enter into employment than the unemployed (ie, more likely to be female, older, less qualified). However, it is useful to look at how changes in the marginally attached group have tracked with economic growth and also with changes in unemployment. This can give us an indication of whether employers are just as likely to source labour from the marginally attached as they are the unemployed.

The following graphs compare annual average percentage changes in real Gross Domestic Product (GDP) with changes in the marginally attached and the unemployed. The first graph, Figure 3, compares economic growth with the unemployed and shows there is a close inverse relationship between economic growth and changes in unemployment (correlation coefficient of -0.79 ).

Figure 3: Changes in GDP and unemployment, 19902008

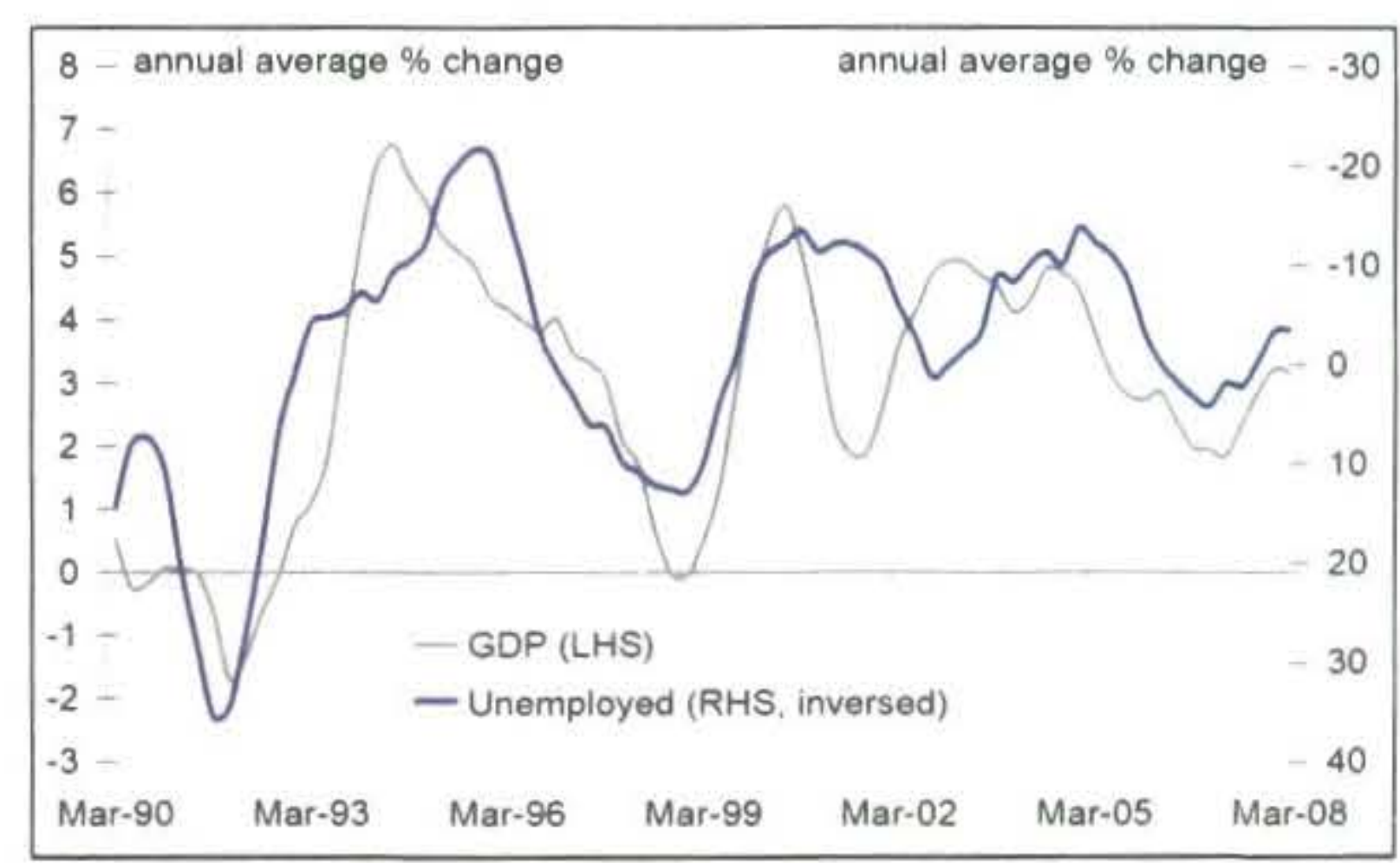

Source: HLFS and GDP data, Statistics New Zealand.

The second graph, Figure 4, shows economic growth and compares this with changes in the number of people marginally attached to the labour force. 
Figure 4: Changes in GDP and the marginally attached, 1990-2008

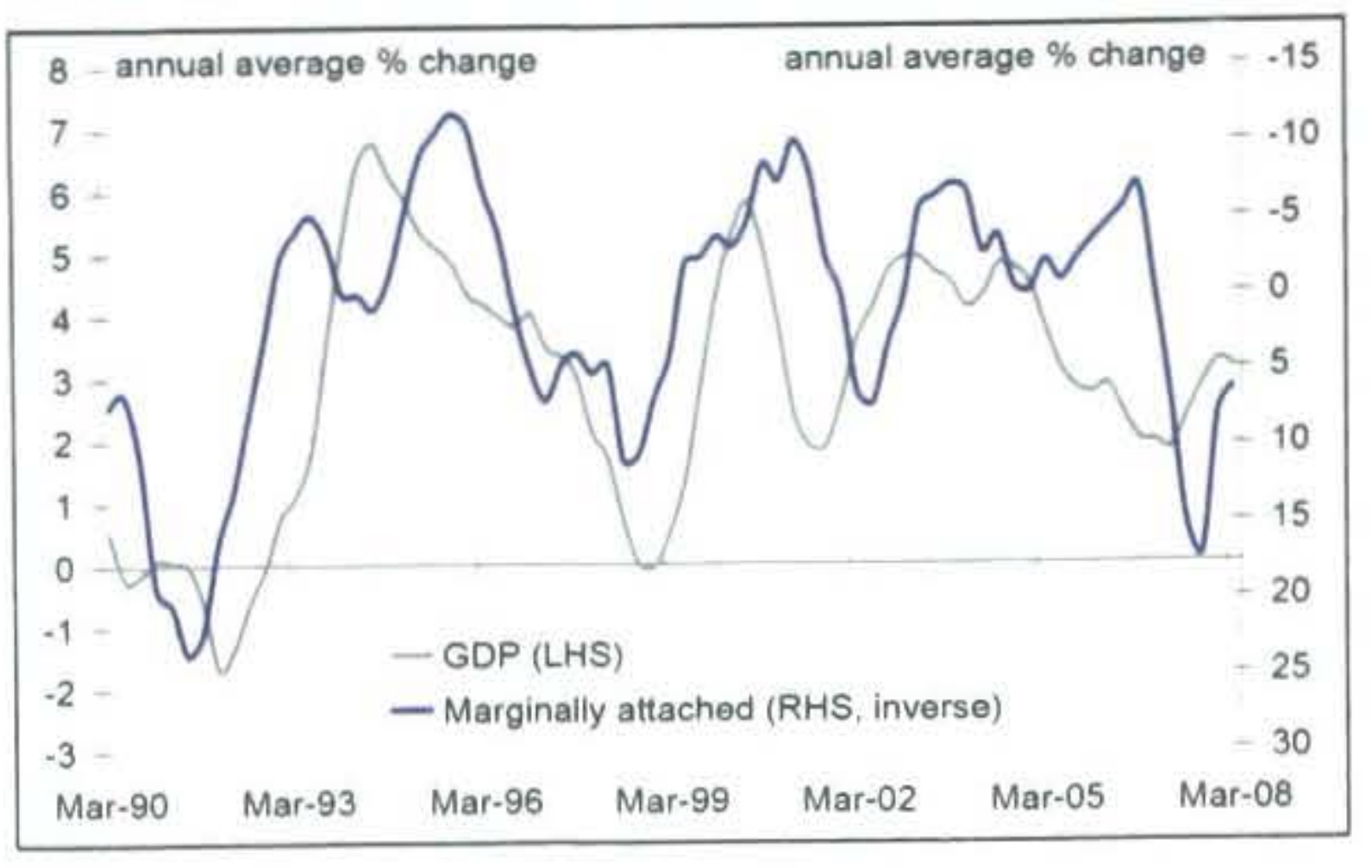

Source: HLFS and GDP data, Statistics New Zealand.

Like unemployment, changes in the number of marginally attached has a relatively close inverse relationship with changes in GDP, despite some divergence over the last three years. While the relationship is not as close as it is for the unemployed (correlation coefficient of -0.64). Figure 4 suggests the marginally attached are affected by economic conditions, just not to the same extent as the unemployed.

There are many different reasons why people are either not available or not seeking work. The numbers of people in some of these groups appear to move in conjunction with economic and labour market conditions while others do not. It has been shown that the number of discouraged workers moves closely with changes in economic conditions (Flain 1973 in Castillo 1998). Indeed. under the latest expansion in employment there has been a large fall in the number of discouraged workers from 11.500 in 1999 to 2,700 in 2008 . Conversely, the number of people attending educational institutions has remained relatively flat. Statistics New Zealand (2004) found that the number of people available but not actively seeking who were studying had actually increased under improving labour market conditions, attributing it to people being more encouraged to engage in education, changes in policies and changes in social expectations. The number of marginally attached retired people also did not show much of a relationship with labour market conditions. As for marginally attached people whose main responsibility was looking after children. Statistics New Zealand found the number of people in this group has generally fallen when labour market conditions improved, although this could also be due to declining birth rates over the last twenty years.

\section{Discussion}

The purpose of this paper was to better understand those people who are classified as marginally attached to the labour force. In particular, it aimed to describe the demographic characteristics of this group and how it compared to the officially unemployed and those not in the labour force. This would, in turn, provide some insight into where future labour supply might be sourced from.

Overall, the characteristics of the marginally attached are more similar to the unemployed than those not in the labour force. For example, within both the unemployed and the marginally attached group Maori and those aged 15-24 are over-represented. However, some characteristics are somewhere in between those of the officially unemployed and those of the not in the labour force group (e.g. gender breakdown, percentage aged 55 and over, percentage with post-school qualifications).

Changes in the number of people marginally attached to the labour force appear to have a relatively close inverse relationship with economic growth. However, under the latest expansion in employment, the number of people marginally attached has fallen only slightly while unemployment has decreased by nearly $50 \%$. Furthermore, some characteristics suggest they are less likely to enter employment than the unemployed (ie, more likely to be female, older, less qualified).

In summary, the marginally attached are a diverse group who do not meet the two conditions of unemployment (actively seeking and available for work) for a vast array of reasons. It therefore follows that a wide range of measures and conditions are needed to attract this group of underutilised labour into the labour market. These could range from improved economic conditions to better access to childcare and flexible work hours to attract people who want to work but who are not available due to childcare duties. Nonetheless, it is likely there is also some natural level of marginal attachment. For example, there will always be a group of people who are looking for a job but are not available due to being engaged in education.

The findings in this paper suggest the marginally attached and unemployed are two distinct groups and therefore should not be combined and viewed as a new official measure of labour market slack, or excess supply. The unemployment rate also has the usual benefits of it being easily understood, having a longer time series and being consistent with ILO definitions allowing international comparisons. This does not mean, however, the jobless rate should be ignored when analysing the health of the labour market. It can be helpful in providing a wider picture of labour underutilisation and can be a more preferable measure for answering certain policy questions around targeting those who want to work.

\section{Future research}

This paper provides a descriptive account of those marginally attached to the labour force by comparing the characteristics of this group with those of the unemployed and those not in the labour force. However, 
further work is needed in New Zealand to look at whether the marginally attached are behaviourally different from the unemployed. In particular, future research could focus on the average length of time spent in the marginally attached category compared with those unemployed and flows between marginal attachment and other labour force states. Overseas studies such as Jones and Riddell (1999) have shown that the transition rates into employment for the marginally attached are different to both the unemployed and the rest of those not in the labour force. It would be beneficial to establish, especially for policy formulation, whether there is a group of people who remain marginally attached for a significant period of time or if there is constant churn within the category.

\section{Acknowledgements}

The author wishes to thank Dirk van Seventer, Simon McLoughlin, Simon Brown and Robert Haig for their comments. The views expressed in this paper do not necessarily represent those of the Department of Labour and any remaining errors are my responsibility.

\section{References}

Akyeampong, E. (1989). Discouraged Workers. Perspectives on Labour and Income, 1, 2.

Castillo, M. (1998). Persons outside the labor force who want a job. Monthly Labor Review, 34-42.

Flaim, P. (1973). Discouraged workers and changes in unemployment. Monthly Labor Review, 95-103.

Hairault, Chéron and Langot. (2007). Job Creation and Job Destruction over the Life Cycle: The Older Workers in the Spotlight. IZA Discussion Paper No. 2597.

Jones, S. and Riddell, W. (1999). The Measurement of Unemployment: an Empirical Approach, Econometrica, 67, 1, 147-162.

Kodrzycki, Y. (2000). Discouraged and other marginally attached workers: evidence on their role in the labour market. New England Economic Review, 36-40.

Laplagne, P., Glover, M. and Shomos, A. (2007). Effects of Health and Education on Labour Force Participation. Staff Working Paper. Melbourne, May.

Mare, D. (1995). Examining Labour Market Outcomes for Maori, Labour Market Bulletin, 1, 116-123.

OECD. (1999). Editorial. Employment Outlook. OECD, Paris.
Rones, P. (1983). The Labour Market Problems of Older Workers. Monthly Labor Review, 3-12.

Statistics New Zealand. (2005). Labour Market Statistics 2004, Article 2.

\author{
Author \\ Simon Hall \\ Work Directions \\ Department of Labour \\ PO Box 3705 \\ Wellington. \\ Simon.Hall@dol.govt.nz
}

